\title{
A Managerial Perspective of Employee Drug Testing in the American Workplace
}

Dr. Ronald M. Knights, Management, Metropolitan State College

\begin{abstract}
The methods of dealing with the use or detection of illicit drugs in the American workplace warrants serious concerns regarding the role that should be undertaken by management regarding this issue. There are a number of approaches which may be utilized, however, it is important for management to take the most appropriate actions necessary to address this concern. The success and visibility of their organization may depend on it.
\end{abstract}

\section{Introduction}

A provocative and challenging subject of this decade concerns the issue of employee drug testing in the American workforce. In accordance with one of this country's most cherished human concepts, "freedom of speech," there appears to be no consensus of opinion among both management and employees regarding the appropriateness of this topic. As a consequence of the foregoing perspective, this paper has been written not only to address what may one day be considered as the "Employee Relations Revolution" of the 1980's, but also as a guide to assist managers in making decisions concerning drug abuse in the work place.

One of the paramount issues confronting the business community in the area of employee drug testing is whether employment related drug abuse is actually severe enough to warrant employers resorting to such a potentially invasive tool as conducting mandatory urinalysis testing of employees for illicit drugs (hereinafter referred to as "employee drug testing").

Inextricably related to this issue is the question of whether drug testing is appropriate and effective in eradicating this perceived problem.

\section{Is Employment Drug Testing Necessary or}

\section{Appropriate in American Industry Today?}

There is a perception in America today that as a nation we are in the midst of a drug crisis. On many levels of society, there is a preoccupation with drugs and their deleterious effects. The media has devoted enormous coverage to drug related incidences.(1) The federal government has declared "war" on drugs(2) and the President of the United States and the First Lady have launched a "national crusade" against drug abuse.(3) On September 15, 1986 President Reagan signed Executive Order No. 12,564(4) which directs all federal agency heads to test employees in sensitive positions for illegal drugs.(5) This executive order has resulted in the drug testing of thousands of federal employees.(6) It is in this environment that management is called upon to objectively evaluate the appropriateness of employee drug testing for its organization.

Responsible management should not blindly evaluate the merits of employee drug testing simply on the basis of pronouncements made in the media or by governmental officials. Rather, it is incumbent upon management to first determine the true dimensions of the drug problem that directly impacts its organization. 
Then management must determine whether the problem is in fact severe enough to warrant the expenditure of significant effort and funds. Finally, it is the responsibility of management to determine whether employee drug testing is the most effective and cost efficient method to address the problem. This managerial evaluation process must include an analysis of certain critical matters. These essential considerations include the following: 1 The actual incidences of drug abuse; 2 Financial and productivity losses resulting from employee drug abuse; 3 The validity and reliability of employee drug testing in identifying employee drug abuse; 4 The financial cost of implementing an employee drug testing program; 5 The effectiveness of employee drug testing in eradicating employee drug abuse; 6 Alternative methods of detecting employee drug abuse.

\section{A. Incidences of Drug Abuse}

There is a drug problem in the United States.(7) The President's Commission on Organized Crime has estimated that 20 million Americans use marijuana at least once a month and six million Americans use cocaine at least once a month.(8) The National Institute on Drug Abuse has partially confirmed these statistics regarding cocaine reporting that five million Americans are cocaine abusers.(9) These specific estimates are consistent with a number of other studies analyzing the incidence of drug use and abuse in the American population.(10) While insightful, these statistics alone are too general to constitute a sufficient inquiry by management into the prevalency of drug abuse.

Unknown to many, the number of persons using drugs in general has actually declined in recent years.(11) The incidence varies depending on the particular type of drug. For instance, two studies have suggested that the use of marijuana in the United States has declined for all age groups since reaching its peak in 1979.(12) The data on cocaine use, however, is not as conclusive. One study indicates that cocaine use continues to increase, but at a slower rate than previously.(13) Seemingly contradictory is a recent report by the National Institute On Drug Abuse that indicates an unabated increase in the number of cocaine-related treatment admissions for a fifteen state area.(14) On balance, studies in this area indicate that there remains a significant portion of the population indulging in illicit drugs, but the overall incidence has either reached a plateau or is actually declining at a slow rate. If the incidence of drug use continues to level off and decline, management may in the future need to reevaluate the magnitude of the potential employee drug abuse problem and, therefore, the appropriateness of its programs to address such a concern.

A study of the demographics of drug abuse may prove useful to management. For example, there has been an overall decrease in the use of marijuana by both males and females, but the decrease for males is greater.(15) Moreover, one study suggests that more women use marijuana than men.(16) On the other hand, the National Institute on Drug Abuse reports that the use of cocaine is greater in the male population than among women.(17) Although some studies suggest that the usage of particular drugs by men and women vary according to the particular drug involved, there does not appear to be a significant difference in the overall use of illicit drugs by men and women.(18) Thus, management should be sensitive to potential drug abuse by both male and female employees.

No age group is free from drug abuse. For instance, forty-four percent of persons between the ages of eighteen and twenty-five (i.e., the typical entry-level employee age group), had used illicit drugs in the past year.(19) However, some age groups appear more active than others in the use of certain illicit drugs. For example, a 1982 National Institute on Drug Abuse study reflects that twenty-eight percent of Americans aged eighteen to twenty-five had tried cocaine, twenty-two percent of persons aged twenty-six to thirty-four had tried cocaine, and only four 
percent thirty-five years or older had tried cocaine.(20) Other demographic information concerning the use of cocaine has been discerned from over one million telephone calls that were made on a cocaine hotline since 1983. Statistics based upon these phone calls reveal a strong relationship between the "baby-boomer" age group and cocaine usage.(21) In particular, the majority of callers were between the ages of twenty-five and forty, averaged more than 14 years of education, with an annual salary of $\$ 25,000$, and included many professionals and executives.(22)

The foregoing information can be instrumental to management if it is dealt with judiciously in evaluating and addressing drug related incidences in the work force.

\section{B. Financial and Productivity Losses Resulting from Employee Drug Abuse}

Illegal drugs are attributed with causing substantial financial and productivity losses for American industry. Due to the illicit nature of the drugs involved, precise figures are not possible and estimates of annual financial losses to American industry from alcohol and drug abuse vary greatly. Estimates range from thirty-three billion dollars(23) to as high as one hundred ten billion dollars.(24) One writer has stated that the annual loss to American businesses from drug abuse alone is approximately fifty billion dollars.(25) Whatever the precise figure, the aggregate losses from drug abuse cannot be characterized as trivial nor viewed lightly by responsible management. Rather, management should focus on direct and derivative losses from employee drug use that can affect the bottom line.

Losses to a company as a result of employee drug abuse may manifest themselves in a number of ways. Paramount among these losses is the reduction of productivity.(26) Another is absenteeism. Absenteeism due to alcohol and drug abuse is estimated to annually cost American industry one billion dollars.(27) Other negative repercussions of employee drug abuse include impaired judgment, and poor coordination.(28) In turn, the aforementioned have a ripple effect resulting in increased tort liabilities and increases in insurance premiums and workman's compensation claims.(29)

It is necessary for management to consider all of the potential losses that its organization may sustain from employee drug abuse. Such an analysis is necessary to make an accurate cost/benefit assessment in the area of employee drug testing.

\section{Validity and Reliability of Employee Drug Testing}

Validity and reliability must be viewed judiciously by management in addressing the issue of employee drug testing. Validity indicates whether a test measures what it purports to measure, and reliability is a measure of how consistent the test results are. These issues lie at the heart of the employee drug testing controversy.

There are many different types of drug tests on the market, two of the most common being the EMIT (enzyme multiplied immunoassay technique) and the GC/MS (gas chromatography/mass spectrometry).(30) The EMIT test is a commonly used testing procedure largely because it is fast, it can detect a number of drugs, and it is inexpensive.(31) Despite its popularity in the workplace, its validity and reliability are highly suspect. Estimates of "false-positive" readings (results falsely indicating the presence of drugs) produced by EMIT tests vary from as low as five percent(32) to as high as sixty-six percent.(33) As stated in a recent article in the Journal of the American Medical Association, "the scientific and clinical basis for the valid use of these tests are questionable".(34) From an organizational standpoint, one expert best summarizes the appropriateness of the EMIT test when he said that "it is almost beyond my ability to comprehend the fact that organizations are actually 
basing employee life-career decisions upon a single EMIT...."(35)

A properly administered and evaluated GC/MS test when used to confirm an EMIT "positive" reading is generally viewed as being virtually one hundred percent accurate.(36) The problem from management's viewpoint is that the GC/MS test is much more expensive and therefore very few employers are likely to use this procedure.(37) Management must consider the difficult issue, however, of what the ultimate purpose is for giving an employee a drug test in the first place. Is it to attempt a quick, cheap fix, even though numerous innocent, productive employees may be falsely accused and discharged for drug abuse? Or is management's purpose to detect those employees who truly need assistance without falsely accusing the remainder of its drug-free personnel? If it is the latter and management wishes to use employee drug testing, then there can be no equivocation. The EMIT alone is unsatisfactory. The GC/MS or some other comparable testing as a confirmation of an initial EMIT is the minimum acceptable procedure.

\section{The Financial Cost of Implementing an Employee Drug Testing Program}

Employee drug testing by Fortune 500 companies has risen from eighteen percent in 1985 to forty percent in 1986,(38) and this increasing trend appears to be continuing.(39) This, however, is not without expense. One writer has estimated that the aggregate annual cost of employee drug testing for large companies and a number of Federal agencies is ninety million dollars and is expected to increase to one hundred eighty million dollars by 1990.(40) Even more relevant to management than these generalized statistics is an estimation of how expensive an employee drug testing program may be. By way of illustration, a hypothetical estimation of such expense for the City of Richmond, Virginia follows.

EMIT test kits vary in cost but fifteen dollars per kit is a frequently cited figure.(41) The estimated cost for the more accurate GC/MS test kit is as high as one hundred dollars.(42) These figures applied to a newly instituted employee drug testing program instituted by the City of Richmond, Virginia can be enlightening.

The City of Richmond, Virginia has recently instituted a drug and alcohol testing program.(43) Start-up costs for this program are $\$ 67,000$.(44) Richmond intends to annually test 4,700 employees. Using the above figures, Richmond will face an annual testing cost of $\$ 70,500$ using the inexpensive, but unreliable, EMIT test. Thus, its first year cost will be $\$ 137,500$. If Richmond officials instead elected the more responsible approach and also utilized the GC/MS test as confirmation, the annual testing expense soars to $\$ 540,500$ and its first year expense will be $\$ 607,500$. In addition, those computations do not include any allowances for potential legal liabilities such as a recent jury award of $\$ 485,000$ in damages awarded an employee who refused to take a surprise urinalysis test.(45) These are not insignificant expenses for a municipality or any employer.

\section{E. The Effectiveness of Employee Drug Testing In Eradicating Employee Drug Abuse}

Authorities are in disagreement regarding the effectiveness of employee drug testing in eliminating drug abuse in the workplace. Certain statistics support the effectiveness of a drug testing program. For instance, the Southern Union Pacific Railroad Company reported that after its institution of a drug and alcohol screening program, there was a seventy-one percent reduction rate in accidents.(46) The Georgia Power Company said injuries within its organization dropped from 5.4 per every 200,000 manhours to 0.49 after a drug testing program was instituted.(47) Along the same lines, the Corporate Director of Human Services for West Coast Grocery Company in Tacoma, Washington said the drug testing program in his company saved $\$ 500,000$ and reduced accidents fifty 
percent in its first year of operation.(48) Also, the Defense Department reported that after two years of drug testing in the United States Navy, the abuse of drugs declined substantially from thirty-seven percent to four percent.(49)

On the other hand, opposing views are just as numerous. One specific concern of relevance was recently stated in the Harvard Business Review, "the value of drug testing is so questionable and the drawbacks so great that no organization should even consider a DTI [drug-testing initiative] without compelling safety or national security reasons."(50) Frequently stated reasons for opposition include the unreliability factor of testing previously discussed.(51) A second cause for criticism is that such tests may detect drug usage occurring days or even weeks prior to testing that may have no bearing whatsoever on employee job performance.(52) Ultimately, the aforementioned concerns can lead to two of the most critical issues that can hinder the effectiveness of any organization, i.e., employee morale and employee productivity.(53) Many managers are aware of this, especially those who manage according to the Theory $\mathrm{Y}$ philosophy because they are aware of the participative concept of this school of thought. They know that drug testing, in all likelihood, may be perceived as an affront to human dignity. Consequently, employees will not perform their jobs to the best of their abilities. In essence, good will and productivity will suffer.

\section{F. Alternative Methods of Detecting Employee Drug Abuse}

Organizations have developed and still are designing alternative ways of dealing with employee drug abuse other than using employee drug testing. The most popular, it appears, is the employee assistance program (EAP).

An EAP is a counseling referral program which is used to serve as a vehicle to detect any disabling work performance problems an employee may have which can result in an adverse impact both for the person and the organization.(54) The program is intended to assist all personnel of an organization, regardless of rank/position. The basic concept of EAPs is specifically geared to deal with a deterioration of work performance.(55) For instance, a supervisor would not approach an employee who is having a drug abuse problem exclusively on those terms. The supervisor would confront the issue by detecting a pattern of work performance deterioration. In essence, the supervisor would address the relationship between drug abuse and work performance.

Are EAP's successful? Apparently 5,000 corporations believe so, voluntarily offering some type of assistance to their employees.(56) On the positive side, those who have analyzed EAP's say that the return on investment for having a program normally yields a two-to-one ratio.(57) This type of saving is exemplified by several specific examples.

According to one source, within two years after AT\&T initiated an in-house employee assistance program, it saved the corporation almost a half a million dollars and accounted for the retention of ninety-seven percent of the employees who used the program.(58) Phillips Petroleum Corporation reported that its EAP nets more than eight million dollars a year, by reducing absenteeism, sick leave, and increasing productivity.(59) Overall, EAPs are considered by certain professionals as being effective in reducing employee drug abuse problems.(60) Based upon the foregoing, management should clearly consider an EAP as a cost efficient and effective alternative to employee drug testing.

\section{Conclusions and Recommendations}

The findings of this study undoubtedly suggest differences of opinions concerning the use and detection of drugs in the American workplace. In many instances, the data relating to these perspectives are inconclusive, complex, and skewed. However, this should not preclude those who are primarily responsible for initiating, directing, and implementing organizational 
efficiency from attempting to deal with this situation in a responsible and effective manner. To help alleviate this confusion, the following points are recommended as a guide to assist management in making decisions in this important and critical area.

1 Management should not allow itself to be swayed solely by the media or political opinions concerning employee drug testing.

2 Management should evaluate the financial costs and benefits of implementing and maintaining an employee drug testing program.

3 Management should weigh the financial costs and benefits of not having an employee drug testing program.

4 Management should investigate both the positive and negative legal ramifications for either implementing or not having an employee drug testing program within its organization.

5 Management should take a close look at the human side of its enterprise. Doing so would enhance its probability of determining the impact an employee drug testing program will have on employee morale and productivity.

6 If management decides to implement an employee drug testing program within its organization, it should look carefully and systematically at the concerns of validity and reliability because, as mentioned previously, this is the crux of the employee drug testing issue.

7 Management should familiarize and educate itself on the various types of alternative methods available, such as Employee Assistance Programs and Wellness Programs. This would be beneficial from the standpoint of enabling management to obtain a wider perspective of what is available in addressing its specific needs and concerns regarding employee drug testing.

By no means should the foregoing be construed as a panacea for dealing with the concerns of illicit drugs in the workforce. However, it is the opinion of this researcher that the above recommendations may possibly assist some managers in coming to grips with the issue of employee drug testing.

\section{References}

1 Kraar, The Drug Trade, FORTUNE, June 20, 1988, at 27.

2 Range, The Demand-Side Drug Fix (Can We Cure The Drug Problem), U.S. NEWS \& WORLD REPORT, Mar. 14, 1988 at 20.

3 Id.

4 See National Fed'n of Fed. Employees v. Carlucci, $680 \mathrm{~F}$. Supp. 416, 421 (D.D.C. 1988), referencing President's Address to the Nation, National Campaign Against Drug Abuse, 22 Weekly Comp. Pres. Doc. 1183, 1185 (Sept. 14, 1986).

5 Exec. Order No. 11,230, 3 C.F.R. 224 (1987)

6 See generally National Fed. Employees v. Carlucci, 680 F. Supp. 416, 421 (D.D.C. 1988). Implementation of this Executive Order has also resulted in innumerable litigations.

7 Kupfer, What To Do About Drugs, FORTUNE, June 20 , 1988 , at 39.

8 McAuliffe, Small Molecule, Large Effects (Alcohol Abuse), 103 U.S.NEWS \& WORLD REPORT, Nov. 30, 1987, at 60.

9 Lamar, Crack: A Cheap and Deadly Cocaine Is A Spreading Menace, 127 TIME, June 2, 1986, at 16.

10 Kozel \& Adams, Epidemiology of Drug Abuse: An Overview, 234 SCIENCE, 1986, at 970.

11 O'Keefe, The Case Against Drug Testing, PSYCHOLOGY TODAY, June 1987, at 34.

12 See Id. Kozel and Adams, supra note 10.

13 Kozel \& Adams, supra Note 10 (citing Gallup poll).

14 Id

15 Id.

16 Id.

17 Id.

18 See Id.

19 Wrich, Beyond Testing: Coping With Drugs At Work, HAR. BUS. REV., 1988, at 120.

20 Olson, Corporate America's Hidden Cocaine Crisis, 11 WORKING WOMAN, at 122.

21 Kozel \& Adams, supra note 12, at 10 (analyzing data from Gallup Poll).

22 Id

23 Lunzer, But I've Never Used Drugs, FORBES, July 13, 1987, at 442 .

24 Finney, The Right to be Tested, PERSONNEL ADMINISTRATOR, March, 1988, at 74 .

25 Holtom, Underwriting Update: Drug Abuse on the Job, 88 Best's Review - Property-Casualty Insurance Edition, April 1988 at 88, (based on report in Best's Underwriting Newsletter, March 1988).

26 Id.

27 Finney, supra note 24 , at 74 .

28 Olson, supra note 20.

29 Holtom, supra note 26 , at 22

30 Hoyt, Finnigan, Nee, Shults, \& Thorne, Drug Testing the Workplace - Are Methods Legally Defensible?, 258 J.A.M.A., July 24,1987 , at 504, hereinafter Hoyt.

31 Council Report, Scientific Issues in Drug Testing, J.A.M.A., at $3110,1987$.

32 Id.

33 See Hudner, Urine Testing for Drugs, 11 Nova L.J. 553, 556 
(1987), (referencing a Center for Disease Control study).

34 Council Report, supra note 31, at 3113.

35 Hoyt, supra note 30 at 507.

36 Council Report, supra note 31.

37 See Hudner, supra note 33 , at 556.

38 Hoyt, supra note 30, see at 504.

39 Mucqyk \& Heshizer, Mandatory Drug Testing: Managing the Latest Pandora's Box, BUSINESS HORIZONS, Mar./Apr. 1988 at 14.

40 Port, Wetter Mark For Drug Testing, BUSINESS WEEK, Jan. 18, 1988, at 68.

41 Mutch, Keeping Drugs Out of the Workplace, PLASTIC WORLD, Feb. 1987, at 59, 60. Accord O'Keefe, supra note 11 , at 35 .

42 Id.

43 Tallman, Guidelines For Drafting A Drug Screening Policy PM, Sept. 1987, at 12, 13.

44 Id.

45 Bureau Of National Affairs Individual Employment Rights No. 14, Nov. 10, 1987 at 1 .

46 Verespej, Emerging Set of Rules, INDUSTRY WEEK, Feb. 9,1987 , at 20 .

47 Id.

48 Id.

49 Howe, Getting Straight Again, Silicon Valley Is Starting To Come To Grips With A Drug And Alcohol Problem: Here's What The Electronics Industry Is Doing, DATAMATION, Aug. 15, 1985, at 31, 32, 40.

50 Wrich, supra note 19 , at 122 .

51 Sonnenstahl, Trice, Studenmeir \& Steele, Employee Assistance and Drug Testing: Fairness And Injustice In the Workplace 11 NOVA L.J. 718-22 (1987).

52 Bearman, The Medical Case Against Drug Testing, HAR. BUS. REV., Jan.-Feb. 1988, at 120, 126: O'Keefe, supra note 11 at 35 .

53 Multby, Why Drug Testing Is A Bad Idea, INC., June, 1987, at 152, 153: O'Keefe, supra note 11 at 35-38.

54 Oher, Assessment Referral, Counseling Key Elements of In-House Programs, OCCUPATIONAL HEALTH \& SAFETY, Dec. 1987, at 22.

55 Sonnenstahl, Trice, Studenmeier \& Steele, supra note 51, at 711-158.

56 Sonnenstahl, supra note 51.

57 Match, supra note 41, at 61 .

58 Lyons, EAPs: The Only Real Cure, MANAGEMENT REVIEW, March 1987 at 38

59 Oher, supra note 54, at 22.

60 Oher, supra note 54, at 22. 